\title{
The Future of Musical Emotions
}

\author{
Dylan van der Schyff ${ }^{1 *}$ and Andrea Schiavio ${ }^{2,3 *}$ \\ ${ }^{1}$ Faculty of Education, Simon Fraser University, Vancouver, BC, Canada, ${ }^{2}$ Institute for Music Education, University of Music \\ and Performing Arts Graz, Graz, Austria, ${ }^{3}$ Music Mind Machine in Sheffield, Department of Music, The University of Sheffield, \\ Sheffield, United Kingdom
}

Keywords: musical emotions, basic emotions, affective science, dynamical systems theory, music cognition

\section{INTRODUCTION}

Basic Emotion Theory proper (BET) has only recently begun to make an appearance in musical research (see Juslin, 1997, 2013a,b). However, much theory and research in music psychology has been driven by a more general assumption that musical emotions should be investigated in terms of discrete $a d-h o c^{1}$ categories associated with the ways specific neural mechanisms respond to musical stimuli (see Schiavio et al., 2016). This has been problematized, however, by studies that show that the physiological changes associated with musical emotions do not always align clearly with those exhibited in association with everyday emotion categories (Krumhansl, 1997, p. 351; Scherer and Zentner, 2001). Such concerns have led some scholars to posit that musical emotions may be somehow different (or perhaps "impoverished") versions of real emotions (Sloboda, 2000). In

OPEN ACCESS

Edited by:

Fausto Caruana,

University of Parma, Italy

Reviewed by:

Marco Viola,

Istituto Universitario di Studi Superior

di Pavia (IUSS), Italy Joel Krueger,

University of Exeter, United Kingdom

*Correspondence:

Dylan van der Schyff dva5@sfu.ca

Andrea Schiavio andrea.schiavio@kug.ac.at

Specialty section: This article was submitted to Theoretical and Philosophical Psychology, a section of the journal Frontiers in Psychology

Received: 03 May 2017 Accepted: 29 May 2017

Published: 19 June 2017

Citation:

van der Schyff $D$ and Schiavio A

(2017) The Future of Musical Emotions. Front. Psychol. 8:988. doi: 10.3389/fpsyg.2017.00988 response to this, other researchers (e.g., Scherer and Coutinho, 2014) have developed models that do away with the notion of basic emotions altogether, preferring instead to describe emotional reactions to music in terms of complex information processing components that combine in various ways to produce relevant outputs (see also Huron, 2006). Still others (Krueger, 2013; van der Schyff, 2013; Schiavio et al., 2016; see also Koelsch, 2013) have suggested that reducing musical experience to a stimulus-response framework-where emotions are thought to be caused in listeners by pre-given stimuli in the environment-may play down the active and creative role living embodied agents play in musical experience.

With this in mind, we offer below a brief critique of BET, suggesting that it may not in fact provide the best way forward for research in musical emotions. We then outline an alternative perspective, drawing on research that employs dynamical systems theory (DST) (Lewis and Granic, 2000; Colombetti, 2014). To conclude, we offer some preliminary suggestions for how this approach might be applied in musical contexts.

Before we begin, it should be noted that musical research that draws on the idea of basic emotions has indeed produced important insights ${ }^{2}$. Such studies are carried out in controlled settings that adhere to high scientific research standards-they offer important sources of data that will have to be taken into consideration by any alternative theoretical orientation. To be clear, then, our aim is not to debunk or discredit the work of researchers endorsing BET. Rather, our goal is simply to outline another perspective that could make important contributions to the dialogue ${ }^{3}$.

\footnotetext{
${ }^{1}$ Indeed, these categories tend to vary from study to study. Some have focused on more "basic" emotions (e.g., joy and sadness), while others introduce categories that might be better described as "moods" (e.g., tenderness or nostalgia). Recent approaches have developed more nuanced models that introduce complex "aesthetic" categories such as wonder and awe. For useful overviews see Juslin and Laukka (2004), Juslin and Västfjäll (2008), Eerola and Vuoskoski (2013), Trost et al. (2013).

${ }^{2}$ This includes the work of Juslin $(1997,2013 \mathrm{a}, \mathrm{b})$ who argues that BET proper should be adopted more widely in musical emotion studies. In line with this, recent research has explored (among other things) the relationship between perceived emotions and physiological changes (Lundqvist et al., 2008), as well as how emotional categories may be recognized consistently across listeners (Fritz et al., 2009).

${ }^{3}$ Indeed, comparisons of research results between competing programs may lead to important new discoveries and avenues of investigation.
} 


\section{BASIC EMOTIONS}

In folk psychology, the notion of "basic emotions" involves the assumption that emotions come in a group of pre-defined categories such as happy, sad, angry, and so on. This idea has been formalized by BET proper, which claims the existence of a small group of "discrete" basic emotions that evolved in response to the challenges our ancestors faced in their everyday life (Ekman, 1980). It is argued that each basic emotion is defined by a dedicated (innate and distinct) neural network, which controls the "affect programs" that give rise to them (Tomkins, 1962, 1963; see also Colombetti, 2014). Here the term "affect programs" refers to the mechanisms that produce "the patterns for these complex organized responses, and which when set off directs their occurrence" (Ekman, 1980 p., 82). Such programs and the responses they trigger (i.e., basic emotions) are thought to be culturally universal and are thus understood to function as "auto appraisals" selected by evolution (Ekman and Friesen, 1971, 1986; Ekman, 1999, 2003). It has also been suggested that because of the supposed categorical fixity of these basic emotions, they might form the "building blocks" from which more complex emotions emerge (Prinz, 2004a,b).

Some critics have raised the question of how, precisely, alleged basic emotions relate to non-basic ones (Ortony and Turner, 1990). And there is an ongoing debate between those who argue that basic and non-basic emotions are continuous (Plutchik, 2001; Prinz, 2004a,b; Clark, 2010), and those who insist that the two involve distinct processes and should thus be studied separately (Damasio, 1994; LeDoux, 1996). Other authors question BET's lack of context sensitivity (Russell, 2003; Barrett, 2006): emotions can be expressed and experienced in various ways and their meanings shift depending on the situation. Attention has also been drawn to the BET methodology, which often employs a forced choice approach (generally between facial expressions and a given scenario). Indeed, research has shown that quite different responses may be given when participants are not constrained by emotional labeling (Russell, 1994). It has also been pointed out that the close correlations that are expected to occur between specific brain areas, autonomic nervous system activity, and the putative affect programs associated with basic emotions are often less consistent than hypothesized (Barrett, 2006). While advocates of BET have responded to such criticisms in various ways (e.g., Ekman and Cordaro, 2011), another more general problem remains concerning the rather arbitrary way basic emotion categories were originally introduced ${ }^{4}$. To be clear, all of this does not negate the observation that emotional episodes involve recurring psycho-physical patterns of behavior that are indeed nameable, and that may bear striking similarities across individuals and groups. Rather, it suggests that we need to develop new approaches for studying such phenomena.

\footnotetext{
${ }^{4}$ This refers to the work of Tomkins $(1962,1963)$, who posited the existence of nine primary affect categories (1962, p. 111-112). While no sustained justification was given by Tomkins for why these categories were chosen, subsets of them have nevertheless been assumed to comprise the basic emotional responses that guide our affective engagements with the world. For a full discussion see Colombetti (2014), p. 36-40.
}

\section{EMOTIONS AS DYNAMIC AND EMERGENT}

Research based on DST suggests that emotional episodes may not be reducible to pre-given response mechanisms in the brain, but rather emerge through developmental processes spanning an integrated body-brain-environment network (Freeman, 2000; Lewis, 2000, 2005). Colombetti (2014, p. 57-82) suggests three mutually informing levels of inquiry that may help us better understand how this is so. The first of these involves the development of the muscular linkages and coordinative structures associated with emotional expression (e.g., facial, vocal, limb, and hand movement). And indeed, research shows that the appearance of recurrent and meaningful patterns of expressive behavior in infants is not best understood wholly in terms of predetermined (i.e., genetic) developmental programs, but rather as emergent properties of the dynamic interaction of a range of environmental and bodily factors (Fogel and Thelen, 1987; Camras and Witherington, 2005). The second level draws on existing work in affective neuroscience that highlights the plasticity and self-organizing nature of neural structures (see Freeman, 1999, 2000). Here, emotional episodes are explored as patterns of convergence (basins of attraction) in the neural trajectories of an agent that may both stabilize and transform due to contingent shifts in the global constraints of the brainbody-world system. The third level focusses on environmental concerns, exploring how agents enact meaningful emotional engagements (i.e., recurrent patterns of relational behavior) with the things and people they interact with, and the situations they live through (Laible and Thompson, 2000; Hsu and Fogel, 2003). From this perspective, emotional episodes are not limited to the skull or the skin of the organism. There is, rather, a strong sense in which they "extend" (Krueger, 2014; Slaby, 2014; Krueger and Szanto, 2016) into environments where agents co-enact meaningful worlds through forms of participatory sense-making (such as music; see Schiavio and De Jaegher, 2017).

In brief, the DST approach explores the active and selforganizing nature of emotional experience as it develops across bodily, neural, and ecological dimensions, suggesting that while emotional episodes can indeed be unique to an individual organism, they may also emerge in ways that are shared between agents with similar biological/social needs and histories of interaction with the environment.

\section{EXPLORING THE DYNAMICS OF MUSICAL EMOTIONS}

It should be noted that work in music cognition has already begun to develop DST approaches. For example, researchers (e.g., Large and Jones, 1999) have investigated how the neural dynamics associated with musical experience actively resonate and self-organize with those of the body and the environment in a recursive or "circular" way. However, such "dynamic attending" to music has been explored mostly in the context of rhythmic entrainment and pitch perception (e.g., Large et al., 2016; see also McGrath and Kelly, 1986). We suggest that future research could develop the emotional implications of this more fully. Indeed, this would contribute to a larger body of inter-disciplinary work that explores the creative, social, embodied, ecological, 
and developmental aspects of musical experience (DeNora, 2000; Leman, 2007; van der Schyff, 2015).

For example, it has been shown that even in contexts that appear to be "passive" (e.g., listening in a concert hall) people play active roles in shaping their engagements with musical environments ${ }^{5}$ (Clarke, 2005; Krueger, 2014)-e.g., by developing "metaphorical," cross-modal, and "narrative" relationships between various temporal, spatial, textural, bodily, social, ecological, and affective dimensions (see Johnson, 2007). Here, DST could be useful for exploring how such experiences are enacted, especially when integrated with phenomenological descriptions ${ }^{6}$.

This orientation could also be developed in contexts involving the production of music (performance, rehearsal, instrumental practice, and so on). Indeed, because musical performance clearly involves the integration of the three levels of description discussed above (bodily/neural/environmental), DST might be used to investigate and describe situations where two or more individuals participate in realizing the same musical event. This could include the use of electrophysiological measurements in association with techniques such as functional near-infrared spectroscopy (fNIRS), which are increasingly adopted in the context of social cognition (Osaka et al., 2015; Pu et al., 2016).

As fNIRS allows for the measurement of hemodynamic activities in participatory settings it could be particularly useful for exploring music-related activities in terms of interpersonal emotional dynamics. These could be analyzed in conjunction with audio and video recordings (to help capture sonic, bodily, and other environmental aspects); as well as through interviews with the participants to better understand how various forms of musically adaptive behavior might initiate (and be driven by) emotional episodes that are both recurrent and new, and how such episodes are experienced by the participants (e.g., as shared and/or as personal). Examples of similar data collection methods come from work by Walton et al. $(2014,2015)$ who have used DST to study perceptions of creativity in interacting musical improvisers (see also Borgo, 2005; Laroche and Kaddouch, $2015)^{7}$.

\footnotetext{
${ }^{5}$ Here one might also consider the ways people use personal music listening devices to regulate their emotions (Skånland, 2013) in everyday life and to transform or "aestheticize" the environments they live though (Bull, 2000, 2007). This could offer yet another avenue to explore from a dynamical perspective.

${ }^{6}$ Here the recently developed " $4 \mathrm{E}$ " model (embodied, embedded, enactive, and extended) associated with enactive cognitive science could provide a general framework for guiding the phenomenological aspects of such research (for a brief overview see van der Schyff, 2017; for a range of more detailed perspectives see Menary, 2010).

${ }^{7}$ On a related note, readers may also be interested to consider a study by Salice et al. (2017) that examines the enmeshed embodied, social, affective, and musical dynamics of a string quartet to explore the phenomenon of "plural self-awareness."
}

\section{REFERENCES}

Barrett, L. F. (2006). Solving the emotion paradox: categorization and the experience of emotion. Pers. Soc. Psychol. Rev. 10, 20-46 doi: 10.1207/s1532 7957pspr1001_2

Borgo, D. (2005). Sync or Swarm: Improvising Music in a Complex Age. New York, NY: Continuum.
In all, we suggest that a DST approach may better capture the (inter)active ways people enact emotional relationships with music, and how such experiences develop diachronically. That is, it may help us better understand how musical emotions emerge and transform developmentally in the context of people's liveswhere stable or recurrent patterns of behavior may come to be experienced in similar ways between embodied agents, and thus be subject to "loose" labeling without being wholly predetermined, fixed, or simply reducible to discrete categories. Likewise, it may also provide insights into the more idiosyncratic ways we engage emotionally with music-e.g., the conscious ways individuals seek out new approaches to music making as a means of creative expression, or as a way of enacting meaningful but highly personal embodied-emotional relationships (aesthetic, social, therapeutic) with the environments they inhabit (DeNora, 2000).

\section{CONCLUSION}

While BET-based approaches will continue to provide many useful insights in more controlled environments, we suggest that the DST perspective may better capture the manifold ways emotional engagement with music unfolds in the complex, embodied, and socially interactive contexts that characterize lived experience. Because this approach sees emotions as emergent and enacted, and not first in terms of pre-given categories or "affect programs," it arguably sidesteps the problematic issue introduced above regarding whether musical emotions correspond with "basic," "real," or "everyday" emotions. In line with this, it would be very interesting to see how the results of musical research that assume a basic emotion approach might be reinterpreted from a DST perspective. Additionally, DST might also shed light on important aspects of musical development in early childhood $^{8}$. Lastly, because DST-based research sees emotionality as inextricable from our embodied and social existence, it could have more general implications for areas such as music education and therapy-perhaps providing ways for teachers, students, therapists, and patients to better understand and discuss their engagements with music and its meaning for their lives.

\section{AUTHOR CONTRIBUTIONS}

The authors have made equal contribution to this paper and are thus both considered as first authors.

\footnotetext{
${ }^{8}$ E.g., the emergence of the (proto)musical forms of embodied-affective communication that characterize the interactions between infants and primary caregivers (see Trevarthen, 2002); as well as the independent and collaborative exploratory musical activities of young children.
}

Bull, M. (2000). Sounding Out the City: Personal Stereos and the Management of Everyday Life. Oxford: Berg.

Bull, M. (2007). Sound Moves: iPod Culture and Urban Experience. London: Routledge.

Camras, L. A., and Witherington, D. C. (2005). Dynamical system approaches in emotional development. Dev. Rev. 25, 328-350. doi: 10.1016/j.dr.2005. 10.002 
Clark, J. A. (2010). Relations of homology between higher cognitive emotions and basic emotions. Biol. Philos. 25, 75-94. doi: 10.1007/s10539-009-9170-1

Clarke, E. F. (2005). Ways of Listening: An Ecological Approach to the Perception of Musical Meaning. New York, NY: Oxford UP.

Colombetti, G. (2014). The Feeling Body: Affective Science Meets the Enactive Mind. Cambridge, MA: The MIT Press.

Damasio, A. (1994). Descartes' Error: Emotion, Reason and the Human Brain. New York, NY: G.P. Putnam's Sons.

DeNora, T. (2000). Music in Everyday Life. New York, NY: Cambridge UP.

Eerola, T., and Vuoskoski, J. K. (2013). A review of music and emotion studies: approaches, emotion models, and stimuli. Music Percept. 30, 307-340. doi: $10.1525 / \mathrm{mp} .2012 .30 .3 .307$

Ekman, P. (1980). "Biological and cultural contributions to body and facial movement in the expression of emotions," in Explaining Emotions, ed A. O. Rorty (Berkeley, CA: University of California Press), 73-102.

Ekman, P. (1999). "Basic emotions," in Handbook of Cognition and Emotion, eds T. Dalgleish and M. J. Power (New York, NY: John Wiley \& Sons Ltd.), 45-60.

Ekman, P. (2003). Emotions Revealed: Understanding Faces and Feelings. London: Weidenfeld \& Nicolson.

Ekman, P., and Cordaro, D. (2011). What is meant by calling emotions basic. Emot. Rev. 3, 364-370. doi: 10.1177/1754073911410740

Ekman, P., and Friesen, W. V. (1971). Constants across cultures in the face and emotion. J. Pers. Soc. Psychol. 17, 124-129. doi: 10.1037/h0030377

Ekman, P., and Friesen, W. V. (1986). A new pan-cultural facial expression of emotion. Motiv. Emot. 10, 159-168. doi: 10.1007/BF00992253

Fogel, A., and Thelen, E. (1987). Development of early expressive and communicative action: reinterpreting the evidence from a dynamical systems perspective. Dev. Psychol. 23, 747-761. doi: 10.1037/0012-1649.23.6.747

Freeman, W. J. (1999). Consciousness, intentionality, and causality. J. Conscious. Stud. 6, 143-172.

Freeman, W. J. (2000). "Emotion is essential to all intentional behavior," in Emotion, Development, and Self-Organization: Dynamic Systems Approaches to Emotional Development, eds M. D. Lewis and I. Granic (Cambridge: Cambridge University Press), 209-235.

Fritz, T., Jentschke, S., Gosselin, N., Sammler, D., Peretz, I., Turner, R., et al. (2009). Universal recognition of three basic emotions in music. Curr. Biol. 19, 573-576. doi: 10.1016/j.cub.2009.02.058

Hsu, H.-C., and Fogel, A. (2003). Stability and transitions in mother-infant faceto- face communication during the first 6 months: a microhistorical approach. Dev. Psychol. 39, 1061-1082. doi: 10.1037/0012-1649.39.6.1061

Huron, D. (2006). Sweet Anticipation: Music and the Psychology of Expectation. Cambridge, MA: The MIT Press.

Johnson, M. (2007). The Meaning of the Body: Aesthetics of Human Understanding. Chicago, IL: University of Chicago Press.

Juslin, P. N. (1997). Can results from studies of perceived expression in musical performances be generalized across response formats? Psychomusicology 16, 77-101.

Juslin, P. N. (2013a). From everyday emotions to aesthetic emotions: towards a unified theory of musical emotions. Phys. Life Rev. 10, 235-266. doi: 10.1016/j.plrev.2013.05.008

Juslin, P. N. (2013b). What does music express? Basic emotions and beyond. Front. Psychol. 4:596. doi: 10.3389/fpsyg.2013.00596

Juslin, P. N., and Laukka, P. (2004). Expression, perception, and induction of musical emotions: a review and a questionnaire study of everyday listening. J. N. Music Res. 33, 217-238. doi: 10.1080/09298210420003 17813

Juslin, P. N., and Västfjäll, D. (2008). Emotional responses to music: the need to consider underlying mechanisms. Behav. Brain Sci. 31, 559-575 doi: 10.1017/S0140525X08005293

Koelsch (2013). "Striking a chord in the brain: the neurophysiological correlates of music-evoked positive emotions," in The Emotional Power of Music: Multidisciplinary Perspectives on Musical Expression, Arousal, and Social Control, eds T. Cochrane, B. Fantini, and K. Scherer (Oxford: Oxford University Press), 177-196.

Krueger, J. (2013). "Empathy, enaction, and shared musical experience: evidence from infant cognition," in The Emotional Power of Music: Multidisciplinary Perspectives on Musical Expression, Arousal, and Social Control, eds T.
Cochrane, B. Fantini, and K. Scherer (Oxford: Oxford University Press), 177-196.

Krueger, J. (2014). Affordances and the musically extended mind. Front. Psychol. 4:1003. doi: 10.3389/fpsyg.2013.01003

Krueger, J., and Szanto, T. (2016). Extended emotions. Philos. Compass 11, 863-878. doi: 10.1111/phc3.12390

Krumhansl, C. L. (1997). An exploratory study of musical emotions and psychophysiology. Can. J. Exp. Psychol. 51, 336-352 doi: 10.1037/11961961.51.4.336

Laible, D. J., and Thompson, R. A. (2000). “Attachment and self-organization,” in Emotion, Development, and Self-Organization: Dynamic Systems Approaches to Emotional Development, eds M. D. Lewis and I. Granic (Cambridge: Cambridge University Press), 298-323.

Large, E. W., and Jones, M. R. (1999). The dynamics of attending: how people track time-varying events. Psychol. Rev. 106, 119-159. doi: 10.1037/0033-295X.106.1.119

Large, E. W., Kim, J. C., Flaig, N., Bharucha, J., and Krumhansl, C. L. (2016). A neurodynamic account of musical tonality. Music Percept. 33, 319-331. doi: $10.1525 / \mathrm{mp} .2016 .33 .3 .319$

Laroche, J., and Kaddouch, I. (2015). Spontaneous preferences and core tastes: embodied musical personality and dynamics of interaction in a pedagogical method of improvisation. Front. Psychol. 6:522. doi: 10.3389/fpsyg.2015. 00522

LeDoux, J. E. (1996). The Emotional Brain. New York, NY: Simon \& Schuster.

Leman, M. (2007). Embodied Music Cognition and Mediation Technology. Cambridge, MA: The MIT Press.

Lewis, M. D. (2000). "Emotional organization at three timescales," in Emotion, Development and Self-Organization, eds M. D. Lewis and I. Granic (Cambridge: Cambridge UP), 37-69.

Lewis, M. D. (2005). Bridging emotion theory and neurobiology through dynamical systems modeling. Behav. Brain Sci. 28, 169-245. doi: 10.1017/S0140525X0500004X

Lewis, M. D., and Granic, I. (eds.). (2000). Emotion, Development, and Self-organization: Dynamic Systems Approaches to Emotional Development. Cambridge: Cambridge University Press.

Lundqvist, L.-O., Carlsson, F., Hilmersson, P., and Juslin, P. N. (2008). Emotional responses to music: experience, expression, and physiology. Psychol. Music 37, 61-90. doi: 10.1177/0305735607086048

McGrath, J. E., and Kelly, J. R. (1986). Time and Human Interaction: Toward a Social Psychology of Time. New York, NY: Guilford Press.

Menary, R. A. (2010). Introduction to the special issue on $4 \mathrm{E}$ cognition. Phenomenol. Cogn. Sci. 9, 459-463. doi: 10.1007/s11097-010-9187-6

Ortony, A., and Turner, T. J. (1990). What's basic about emotions? Psychol. Rev. 97, 315-331.

Osaka, N., Minamoto, T., Yaoi, K., Azuma, M., Minamoto Shimada, Y., and Osaka, M. (2015). How two brains make one synchronized mind in the inferior frontal cortex: fNIRS-based hyperscanning during cooperative singing. Front. Psychol. 6:1811. doi: 10.3389/fpsyg.2015. 01811

Plutchik, R. (2001). The nature of emotions. Am. Sci. 89, 334-350. doi: $10.1511 / 2001.4 .344$

Prinz, J. J. (2004a). “Embodied emotions," in Thinking about Feeling, ed R. C. Solomon (Oxford: Oxford University Press), 44-60.

Prinz, J. J. (2004b). Gut Reactions: A Perceptual Theory of Emotion. New York, NY: Oxford University Press.

$\mathrm{Pu}$, S., Nakagome, K., Yamada, T., Itakura, M., Yamanashi, T., Yamada, S, et al. (2016). Social cognition and prefrontal hemodynamic responses during a working memory task in schizophrenia. Sci. Rep. 6:22500. doi: $10.1038 /$ srep 22500

Russell, J. A. (2003). Core affect and the psychological construction of emotion. Psychol. Rev. 110, 145-172. doi: 10.1037//0033-295X.110.1.145

Russell, J. A. (1994). Is there universal recognition of emotion from facial expression? A review of the cross-cultural studies. Psychol. Bull. 115, 102-141. doi: 10.1037/0033-2909.115.1.102

Salice, A., Høffding, S., and Gallagher, S. (2017). Putting plural selfawareness into practice: the phenomenology of expert musicianship. Topoi. doi: $10.1007 / \mathrm{s} 11245-017-9451-2$ 
Scherer, K. R., and Coutinho, E. (2014). "How music creates emotion: a multifactorial process approach," in The Emotional Power of Music, Multidisciplinary Perspectives on Musical Arousal, Expression, and Social Control, eds T. Cochrane, B. Fantini, and K. R. Scherer (Oxford: Oxford University Press), 121-145.

Scherer, K. R., and Zentner, M. R. (2001). "Emotional effects of music: production rules," in Music and Emotion: Theory and Research, eds P. N. Juslin and J. A. Sloboda (Oxford: Oxford University Press), 361-392.

Schiavio, A., and De Jaegher, H. (2017). "Participatory sense-making in joint musical practices," in The Routledge Companion to Embodied Music Interaction, M. Lesaffre, M. Leman, and P. J. Maes (New York, NY; London: Routledge), 31-39.

Schiavio, A., van der Schyff, D., Cespedes-Guevara, J., and Reybrouck, M. (2016). Enacting musical emotions. Sense-making, dynamic systems, and the embodied mind. Phenomenol. Cogn. Sci. doi: 10.1007/s11097-016-9 477-8

Skånland, M. S. (2013). Everyday music listening and affect regulation: the role of MP3 players. Int. J. Qual. Stud. Health Well-being 8:20595. doi: 10.3402/qhw. v8i0.20595

Slaby, J. (2014). "Emotions and the extended mind," in Collective Emotions, eds M. Salmela and C. von Scheve (Oxford: Oxford University Press), 32-46.

Sloboda, J. A. (2000). "Musical performance andemotion: issues and developments," in Music, Mind and Science, ed S. W. Yi (Seoul: Western Music Research Institute), 220-238.

Tomkins, S. S. (1962). Affect, Imagery, and Consciousness, Vol. 1. New York, NY: Springer.

Tomkins, S. S. (1963). Affect, Imagery, and Consciousness, Vol. 2. New York, NY: Springer.

Trevarthen, C. (2002). "Origins of musical identity: evidence from infancy for musical social awareness," in Musical Identities, eds R. A. R. MacDonald,
D. J. Hargreaves, and D. Miell (Oxford: Oxford University Press), 21-38.

Trost, W., Ethofer, T., Zentner, M., and Vuilleumier, P. (2013). Mapping aesthetic musical emotions in the brain. Cereb. Cortex 22, 2769-2783. doi: 10.1093/cercor/bhr353

van der Schyff, D. (2013). Emotion, embodied mind, and the therapeutic aspects of musical experience in everyday life. Approaches Music Ther. Special Music Educ. 5, 20-58.

van der Schyff, D. (2015). Music as a manifestation of life: exploring enactivism and the 'Eastern perspective' for music education. Front. Psychol. 6:345. doi: 10.3389/fpsyg.2015.00345

van der Schyff, D. (2017). Refining the model for emotion research: a $4 \mathrm{E}$ perspective. Construct. Found. 12, 227-229.

Walton, A., Richardson, M. J., and Chemero, A. (2014). Self-organization and semiosis in jazz improvisation. Int. J. Signs Semiotic Syst. 3, 12-25. doi: 10.4018/ IJSSS.2014070102

Walton, A., Richardson, M. J., Langland-Hassan, P., and Chemero, A. (2015). Improvisation and the self-organization of multiple musical bodies. Front. Psychol. 6:313. doi: 10.3389/fpsyg.2015.00313

Conflict of Interest Statement: The authors declare that the research was conducted in the absence of any commercial or financial relationships that could be construed as a potential conflict of interest.

Copyright (c) 2017 van der Schyff and Schiavio. This is an open-access article distributed under the terms of the Creative Commons Attribution License (CC BY). The use, distribution or reproduction in other forums is permitted, provided the original author(s) or licensor are credited and that the original publication in this journal is cited, in accordance with accepted academic practice. No use, distribution or reproduction is permitted which does not comply with these terms. 